\title{
Importance of histological verification of mediastinal lymphadenopathy in exact staging of non-small cell bronchogenic carcinoma
}

\author{
Hytych $\mathrm{V}^{1}$, Pohnan $\mathrm{R}^{2,3}$, Taskova $\mathrm{A}^{1}$, Horazdovsky $\mathrm{P}^{1}$, Konopa $\mathrm{Z}^{1}$, Demes $\mathrm{R}^{1}$, Cermak $\mathrm{J}^{1}$, \\ Vrabcova $\mathrm{A}^{1}$, Hoferka $\mathrm{P}^{1}$
}

Department of Thoracic Surgery, Thomayer's Hospital, Prague, Czech Republic. vladislav.hytych@ftn.cz

\begin{abstract}
Background: Diagnostics and treatment of bronchogenic non-small cell lung carcinoma is a severe clinical problem. Radical surgery is the major treatment modality with the highest chance for a long-time survival. The aim of the study was to map metastasizing of bronchogenic non-small cell lung carcinoma into homolateral mediastinal lymph nodes and to assess the importance of histological verification of mediastinal lymphadenectomy for exact staging and treatment.

Methods: Study of 29 patients with non-small cell lung carcinoma in stage IIIa, IIIb and IV (TNM classification) diagnosed from September 2006 to March 2007, with mediastinal lymph nodes invasion according to CT, and with subsequent mediastinal lymph node dissection during autopsy.

Results: $50 \%$ of the right upper lobe tumors metastasized into group 1 nodes (N1-N4) and 50\% into group 3 (N7). $66 \%$ of the right lower lobe tumors metastasized into group 3 nodes (N7) and $33.3 \%$ into group 1 (N1-4). $20.0 \%$ of the left upper lobe tumors metastasized into group 1 nodes (N1-4), 33.0\% into group 2 (N5-6), 25.0\% into group 3 (N7) and $16.7 \%$ into group 4 (N8-9). 23.5\% of the left lower lobe tumors metastasized into group 1 nodes (N1-4), 23.5\% into group 2 (N5-6), $23.5 \%$ into group 4 (N8-9) and 29.5\% into group 3 (N7). 27.6\% of examined patients had false positivity of lymph node metastasis according to CT.

Conclusion: Histological verification of suspect mediastinal lymph nodes via Endobronchial Ultrasound Biopsy (EBUS) or mediastinoscopy or thoracoscopy is crucial for determining the stage of the disease according to the TNM classification. False positivity of imaging methods in diagnostics of non-small cell brochogenic carcinoma can contraindicate up to quarter of potentially operable patients (Tab. 3, Ref. 11). Text in PDF www.elis.sk. Key words: mediastinal lymphadenopathy, bronchogenic carcinoma, lung cancer.
\end{abstract}

Lung cancer is one of the most frequent malignant tumors (1). 82606 cases of malignancies were reported in the Czech Republic's National Oncological Register in 2010, that was $4 \%$ increase compared to 2009. 27834 patients died in the consequence of malignant diseases ( $0.6 \%$ increase). The most common tumors in 2010 were colorectal carcinoma, lung cancer, breast malignancies in women and prostate carcinoma in men.

6532 cases of malignant neoplasmas of trachea, bronchus and lung were reported in the Czech Republic in 2010, that was $1.5 \%$ increase compared to 2009.4641 of newly diagnosed were men (incidence 89.9/100 000). Women incidence was 35.3/100 000 (1891

'Department of Thoracic Surgery, Thomayer's Hospital, Prague, Czech Republic, ${ }^{2}$ Department of Surgery, Central Military Hospital - Faculty Military Hospital, 2nd Faculty of Medicine, Charles University, Prague, Czech Republic, and ${ }^{3}$ Chair of Field Surgery, Faculty of Military Health Sciences, University of Defence, Hradec Kralove, Czech Republic

Address for correspondence: V. Hytych, MD, Department of Thoracic Surgery, Thomayer'sHospital, Videnska 800,CZ-14059Prague4, Czech Republic.

Acknowledgement: We would like to thank to our colleagues from Department of Pathology, Department of Anesthesiology, Resuscitation and Intensive Care Medicine and Department of Pulmonary Medicine of Thomayer's Hospital in Prague. new cases). Men incidence has decreased and stagnated over the incidence in women for a long period in the Czech Republic. Lung cancer remains the most frequent cause of death of malignancy in men in Czech Republic. The half of cases were discovered in the clinical stage IV (2).

228190 cases of new lung malignancies were reported in the United States in 2010, that was $13.7 \%$ newly diagnosed malignant tumors. 159480 patients died $(27.5 \%$ of all cause of death of malignancy). Relative incidence was $75.2 / 100000$ persons in men, 52.3/100 000 persons in women and in total 63.5/100 000 persons. US National Cancer Institute describes differences in Caucasians, Afroamericans, Asiatics, Indians and Latinos.

Specific mortality in the United States in 2010 was 63.5/100 000 persons in men and 39.2/100 000 persons in women and in total $51.35 / 100000$ persons. $56 \%$ new cases were discovered in the clinical stage IV and their 5-year survival was 3.9\%. $15 \%$ of the patients were diagnosed in stage I and their 5-year survival was $53.5 \%$. In $22 \%$ of cases were detected metastastases in mediastinal lymph nodes and 5-year survival was $26.1 \%$ (3).

The aim of this prospective study was to map metastasizing of bronchogenic non-small cell lung carcinoma into homolateral mediastinal lymph nodes and to assess the importance of histo- 


\section{5-587}

logical verification of mediastinal lymphadenectomy for exact staging and treatment.

\section{Methods}

We included into the study patients with non-small cell lung carcinoma diagnosed in the Department of Respiratory Medicine of the Thomayer's Hospital, Prague, from September 2006 to March 2007. Inclusion criteria were the following: patients with stage IIIa, IIIb and IV (TNM classification) with mediastinal lymph nodes invasion according to $\mathrm{CT}$, and died of generalization or due to terminal complication during generalization, and with mediastinal lymph node dissection during autopsy (all zones 1-4, lymph nodes No. 1-9 according TNM classification vol. 7).

\section{Results}

There were in total 29 patients, 21 men $(72.4 \%)$ with average age 71.8 years ( $50-85$ years) and 8 women $(27.6 \%)$ with average age 63.5 years ( $47-83$ years).

Malignancy in family history was reported in 9 cases $(24.1 \%)$ and bronchogenic carcinoma was reported in 3 cases.

In personal history was malignancy reported in 4 cases $(13.8 \%)$, and one patient underwent surgery and adjuvant chemotherapy for bronchogenic carcinoma.

The most frequent comorbidity was arterial hypertension (45.2\%) followed by ischemic heart disease and chronic obstructive pulmonary disease $(62.1 \%)$ and diabetes mellitus $(31.0 \%)$.

There were 25 smokers $(86.2 \%)$, who had smoked in average 38.8 years (20 to 63 years) and had smoked in average 250591 cigarettes (56 575-536 550). 12 patients quit smoking (25.8\%) and the mean non-smoking time was 3.0 years (2-25 years).

The most frequent tumor localization was the upper right lobe (URL) - 9 cases, 15 patients had tumor in the left lung, 8 cases in the lower lobe (LLL) and 7 cases in the upper lobe (LUL). The mean tumor size was $63.8 \mathrm{~mm}$.

In the time of diagnosis were mediastinal lymph node metastases detected in 21 patients $(69,0 \%)$ according to $\mathrm{CT}, 82.2 \%$ hilar lymph nodes N1 were affected, $72.4 \% \mathrm{~N} 2$ and $31.0 \% \mathrm{~N} 3$.

Bronchoscopy showed pathological findings in 25 patients (86.2\%): 16 stenosis of subsegmental bronchial tube, 4 granulations, in 5 cases inflammatory changes. Only in 2 patients ( $7 \%)$ cytological examination didn't raised suspicion of non-small cell lung carcinoma.

Histopathological examination confirmed 5 types of the lung carcinoma (Tab.1).

In total 755 mediastinal lymph nodes were dissected, in average 26 nodes per patient. Metastases were detected in 264 lymph nodes, representing $35.0 \%$ of all collected nodes. The mean value of the affected lymph nodes was 9.1 lymph nodes with metastases per patient.

In case of the lymph node positivity, all lymph nodes in the appropriate stage were affected. In case of the lymph node negativity, all the lymph nodes in the appropriate stage were without metastasis.
Tab. 1. Histopathological finding.

\begin{tabular}{lcc}
\hline Type & No. & $\%$ \\
\hline Squamous cell carcinoma & 15 & 51.7 \\
Adenocarcinoma & 7 & 24.1 \\
Bronchioalveolar carcinoma & 1 & 3.5 \\
Anaplastic carcinoma & 4 & 13.8 \\
Large cell carcinoma & 2 & 7.0 \\
\hline
\end{tabular}

Tab. 2. Comparison of CT and autopsy findings of mediastinal lymph nodes.

\begin{tabular}{lc}
\hline CT/ autopsy & $\%$ \\
\hline conformity & 62.1 \\
CT false negative finding & 10.3 \\
CT false positive finding & 27.6 \\
\hline
\end{tabular}

Tab. 3. Cause of death.

\begin{tabular}{lcc}
\hline The cause & No. & $\%$ \\
\hline Generalization & 11 & 37.9 \\
Pneumonia & 14 & 48.3 \\
Pulmonary embolism & 1 & 3.4 \\
Acute pancreatitis & 1 & 3.4 \\
stroke & 2 & 7.0 \\
\hline
\end{tabular}

Tumors of the right upper lobe metastasized in $50.0 \%$ into group 1 nodes (stages N1-N4) and in $50.0 \%$ into group 3 nodes (stage N7).

There were no metastasis of the tumors of the right middle lobe.

Tumors of the right lower lobe metastasized in $66.7 \%$ into group 3 (stage N7) and in $33.3 \%$ group 1 nodes (stages N1-N4).

In tumors of the left upper lobe were metastases detected in $20.0 \%$ in group 1 nodes (stages $\mathrm{N} 1-\mathrm{N} 4$ ), in $33.0 \%$ into group 2 nodes (stages N5-N6), in $25.0 \%$ into group 3 nodes (stage N7) and in $16.7 \%$ into group 4 nodes (stages N8-N9).

Tumors of the left lower lobe metastasized in $23.5 \%$ into group 1 nodes (stages N1-N4), $23.5 \%$ into group 2 nodes (stage N5-N6), $23.5 \%$ into group 4 nodes (stage N8-N9) and $29.5 \%$ into group 3 nodes (stage N7).

More than 1/4 of examined patients had false positivity of lymph node metastasis according to CT (Tab. 2). 10 patients underwent chemotherapy. These patients were treated by combination of cisplatin and navelbine. All the patients suffered from minor side effects of chemotherapy. 5 patients died of generalization or due to terminal complication during chemotherapy.

8 patients were treated by actinotherapy. All the patients suffered from minor side effects of actinotherapy. 3 patients died of generalization or due to terminal complication during actinotherapy. 5 patients had adjuvant chemoradiotherapy.

All the patients died during 12-1644 days. The average survival was 221.7 days. The most frequent cause of death was generalization of the disease or bronchopneumonia (Tab.3).

\section{Discussion}

There were in total diagnosed 29 patients with non-small cell lung carcinoma in stage IIIb and IV (TNM classification) with 
mediastinal lymph nodes invasion, who died of generalization or due to terminal complication during generalization.

In total 755 mediastinal lymph nodes were dissected, in average 26 nodes per patient. In 264 lymph nodes were detected metastases, representing $35.0 \%$ of all collected nodes. The mean value of the affected lymph nodes was 9.1 lymph nodes with metastases per patient.

Relatively a high number of mediastinal lymph nodes affection was caused by late stage of the disease (stage IIIb and IV). In case of one lymph node positivity in an appropriate stage were affected all the lymph nodes in the appropriate stage. In case of the lymph node negativity were all the lymph nodes in the appropriate stage without metastasis.

Determining the extent of the lung cancer is essential for setting of the adequate therapy. Similar to other malignancies, we used the TNM classification vol.7.

The aim of the diagnostics is to determine the histological classification of tumor (typing), malignity degree (grading), the extent of the malignant process (staging) and the performance status with comorbidities (6).

Diagnostics is based on the imaging methods, bronchoscopic examination, cytological and histological examination (7).

In 21 patients $(69.0 \%)$ were mediastinal lymph node metastasis detected at the time of diagnosis. According to CT were affected $82.2 \%$ hilar lymph nodes N1, $72.4 \%$ homolateral N2 and $31.0 \%$ contralateral N3 lymph nodes.

4 patients $(13.8 \%)$ were classified in the stage IIIa, 4 patients $(17,2 \%)$ in the stage IIIb and 20 patients $(69.0 \%)$ in the stage IV.

Comparison of CT findings and the results of dissected mediastinal lymph nodes in the autopsy showed confirmation in 62.1 $\%$, CT false negative finding was in $10.3 \%$ and $\mathrm{CT}$ false positive finding was $27.6 \%$. Only $2 / 3$ correctness of CT examination was caused of advanced stages of the disease with many mainly respiratory complications. Described enlarged false positive lymph nodes were caused mainly of pneumonitis behind tumor obstruction with inflammatory lymph nodes reaction.

$27.6 \%$ of examined patients had false positivity of lymph node metastasis according to CT. CT false positivity in diagnostics of lung malignancies can contraindicate up to $1 / 4$ of potentially resectable patients, therefore histological verification of suspect mediastinal lymph nodes via EBUS (Endobronchial Ultrasound Biopsy) or mediastinoscopy or thoracoscopy is requisite (8).

\section{Conclusion}

Imaging methods false positivity in diagnostics of non-small cell brochogenic carcinoma, can contraindicate up to quarter of potentially operable patients.

Histological verification of suspect mediastinal lymph nodes via Endobronchial Ultrasound Biopsy (EBUS) or mediastinoscopy or thoracoscopy is crucial for determining the stage of the disease according to the TNM classification.

\section{References}

1. Hytych V, Vernerová A, Horažd'ovský P. Včasná diagnostika karcinomu plic. Causa Subita 2006; 9: 261-266.

2. ÚZIS ČR, Aktuální informace č. 5/2013, Incidence zhoubných novotvarů v ČR v roce 2010, http://www.uzis.cz/publikace/novotvary/2010.

3. U.S. National Institutes of Health, National Cancer Institute: NonSmall Cell Lung Cancer (PDQ): http://seer.cancer.gov/statfacts/html/ lungb.html).

4. Goldstraw P, Crowley J, Chansky $\mathbf{K}$ et al. The IASLC lung cancer staging project: proposals for the revision of the TNM stage groupings in the forthcoming (seventh) edition of the TNM classification of malignant tumors. J Thorac Oncol 2007; 2: 706-714.

5. Rusch VW, Asamura H, Watanabe H, Giroux DJ, Rami-Porta R, Golgstraw P. The IASLC Lung Cancer Staging Project. A proposal for New International Lymph Node Map in the Forthcoming Seneth Edition of the TNM Classficationfor Lung Cancer. J Thorac Oncol 2009; 4: 568-577.

6. Hytych V, Taskova A, Horazdovsky P, Konopa Z, Demes R, Cermak J, Vrabcova A, Hoferka P, Pohnan R. Importance of systemic mediastinal lymphadenectomy in exact staging of bronchogenic carcinoma. Bratisl Lek Listy 2013; 114 (10: 569-572.

7. Detterbeck FC, Mazzone PJ, Naidich DP, Bach PB. Screening for Lung Cancer: Diagnosis and Management of Lung Cancer, 3rd ed: American College of Chest Physicians Evidence-Based Clinical Practice Guidelines. Chest 2013; 143 (Suppl 5): e78S-92S.

8. Annema JT, van Meerbeeck JP, Rintoul RC, Dooms C, Deschepper E, Dekkers OM et al. Mediastinoscopy vs endosonography for mediastinal nodal staging of lung cancer: a randomized trial. JAMA 2010; 304 (20): 2245-252.

9. Wang X, Zheng L, Ling L, Zhang SY, Xie ZM, Yu H, Su XD, Wang JY, Huang ZF, Yang MT, Rong TH. Prospective comparison of CT versus mediastinoscopy in preoperative evaluation of mediastinal lymph node status in patients with non-small cell lung cancor. Zhonghua Zhong Liu Za Zhi 2009; 31 (1): 42-44.

10. Annema JT, van Meerbeeck JP, Rintoul RC, Dooms C, Deschepper E, Dekkers OM, De Leyn P, Braun J, Carroll NR, Praet M, de Ryck F, Vansteenkiste J, Vermassen F, Versteegh MI, Veseliç M, Nicholson AG, Rabe KF, Tournoy KG. Mediastinoscopy vs endosonography for mediastinal nodal staging of lung cancer: a randomized trial. JAMA 2010; 304 (20): 2245-252.

11. Benej R, Harustiak S. Endoskopický staging bronchogenného karcinomu. 55-59. In: Chovan L et al. Škola pneumológie a ftizeológie. Bratislava: Respiro, 2000. 